\title{
Mito e Magia em Claude Lévi-Strauss
}

\author{
MYTH AND MAGIC IN CLAUDE LÉVI-STRAUSS
}

Tatiane Aparecida de Almeida*

\section{RESUMO}

Esta comunicação tem por objetivo apresentar um breve estudo sobre a temática "Mito e Magia no pensamento de Claude Lévi-Strauss", que será norteado a partir dos textos A Estrutura dos Mitos, O feiticeiro e sua magia e A eficácia simbólica, de autoria do antropólogo e filósofo francês. Entende-se por Mito um sistema de operações lógicas que opera mediante vários códigos como, por exemplo, a linguagem. E, por magia, especificamente o papel do mago, como uma disposição para se estabelecer um equilíbrio entre o pensamento normal e o pensamento patológico que resultará na atividade mental exercida através das atitudes do mago no ritual, considerando que tal discussão é norteada através da vertente psicológica. Nessa perspectiva, propomos em um primeiro momento, discutir a estrutura dos mitos e, posteriormente, a estrutura da magia e, no último momento, promover um diálogo entre os dois conceitos sob a ótica do senso religioso contemporâneo.

Palavras-chave: Magia. Mito. Lévi-Strauss. Estruturalismo.

\section{ABSTRACT}

This communication aims to present a brief study on the theme Myth and Magic in Claude Lévi-Strauss thought. The study will be guided by the studies of the texts The Structure of Myths, The Sorcerer and his Magic and The Symbolic Effectiveness, authored by the French anthropologist and philosopher. It is understood by Mito a system of logical operations that operates through several codes, as for example, in the language. And by magic, specifically, the role of the magician as a disposition to establish a balance between normal thinking and pathological thinking which will result in the mental activity exercised through the magician's attitudes in ritual, considering that such a discussion is guided through the strand psychological. From this perspective, we propose at first, to discuss the structure of myths and, later, the structure of magic, and at the last moment, to promote a dialogue between the two concepts from the perspective of the sense religious contemporary.

Keywords: Magic. Myth. Lévi-Strauss. Structuralism.

Claude Lévi-Strauss (1908-2009) foi um antropólogo francês que dedicou boa parte de seu trabalho à escrita de uma tetralogia, denominada Mitológicas, que faz referência ao estudo dos mitos.

Dada essa informação, nota-se que não será possível, neste ensaio, contemplarmos todas ou grande parte das obras do autor no que se refere à temática, tendo em vista que se trata de um material com volume muito extenso.

\footnotetext{
* Mestra em Ciências da Religião pela Pontifícia Universidade Católica de Minas Gerais. Doutoranda do Programa de Pós-graduação em Ciências da Religião na mesma universidade. E-mail: tatyanealmeida-10@hotmail.com
} 
Em contrapartida, na obra Antropologia Estrutural, publicada originalmente em 1958, o autor reúne diversos textos que fazem interface com a teoria estruturalista, bem como promove a reflexão da antropologia enquanto método, elencando também alguns problemas do ensino da disciplina. $\mathrm{O}$ antropólogo salienta também outras relações que são distribuídas nos capítulos da obra, que perpassam os temas da linguagem, da magia, da arte e da mitologia dentre outros.

Diante disso, propomos um estudo sucinto a fim de associar a temática do mito à categoria da magia, tal qual é explorado em três textos que constituem a obra.

Nessa comunicação utilizaremos o texto: A estrutura dos Mitos, obra que, segundo nosso entendimento, nos dá aporte para um primeiro contato com as ideias a respeito do mito; e no que tange à magia, os textos: $A$ eficácia simbólica e Ofeiticeiro e sua magia.

Ambos os textos nos remetem ao estudo da magia e, especialmente, ao seu agente - mago - a partir da estrutura de pensamento que se dá majoritariamente através do perfil psicológico e da análise da cultura da sociedade, uma vez que, para Lévi-Strauss, os mitos são capazes de promover o entendimento do funcionamento da cultura na qual ele se estabelece e se perpetua.

Claude Lévi-Strauss, de acordo com Lidório (2009, p. 8), no século XX, foi considerado o fundador da antropologia estruturalista que tem por princípio a noção estrutural do intelecto, ou seja, dialoga com a existência de regras estruturantes que partem da cultura e que se desenvolvem na mente humana a fim de compreender a coerência do sistema.

Lidório (2009, p. 8) também destaca que Lévi-Strauss recorreu a duas fontes principais para desenvolver tal metodologia estrutural. Primeiro, recorreu à corrente psicológica criada por Wundt e, depois, ao trabalho realizado no campo da linguística por Saussure, denominado "Estruturalismo". 
O Estruturalismo dá um grande impulso à linguística de forma geral ao defender que é necessário compreender o padrão mental, de pensamento e comunicação de um povo, a fim de compreender a sua cultura. Nesta época métodos fonológicos passam a ser aplicados para estudos culturais. A finalidade maior é encontrar o que foi chamado de pensamento coletivo, pois este aglutinaria impressões e valores de um povo. Valoriza-se o registro (e interpretação) de lendas e mitos. (LIDÓRIO, 2009, p. 8).

Desse modo, surgiu a necessidade de se obter registros e promover as diversas interpretações dos mitos diante de diversos retratos de cultura. Um dos principais antropólogos do século XX, importante assim como Claude LéviStrauss, Cliford Geertz (2008, p. 14), ao abordar a interpretação das culturas, destacou o trabalho de Clyde Kluckhohn que conceitua a cultura como: (1) "o modo de vida global de um povo"; (2) "o legado social que o indivíduo adquire do seu grupo"; (3) "uma forma de pensar, sentir e acreditar"; (4) "uma abstração do comportamento"; (5) "uma teoria, elaborada pelo antropólogo sobre a forma pela qual um grupo de pessoas se comporta realmente"; (6) "um celeiro de aprendizagem em comum"; (7) "um conjunto de orientações padronizadas para os problemas recorrentes"; (8) "comportamento aprendido"; (9) "um mecanismo para a regulamentação normativa do comportamento"; (10) "um conjunto de técnicas para se ajustar tanto ao ambiente externo como em relação aos outros homens"; (11) "um precipitado da história". Nessa asserção, o mito pode ser compreendido como um elemento cultural que interfere diretamente no modo de viver do homem por se caracterizar enquanto um constructo do mesmo e como um retrato de um tempo fundante, de modo que o relato oral é uma prática discursiva sobre os acontecimentos primeiros, in ïlo tempore, ou seja, naquele tempo, ocorrido no princípio dos tempos que nos remete a uma narrativa mítica de fundação, onde o pensamento mítico do ser humano é estimulado a refletir mediante os traços da cultura local e real a partir do viés do ato fundador.

Sobre isso, Lévi- Strauss (1970c, p. 225) considera que a mitologia é um dos capítulos de estudo da etnologia, aquela que estuda os fatos e documentos colhidos no âmbito da antropologia cultural e social e que promovem uma apreciação analítica e comparativa das culturas. 
Contudo, por esse mesmo motivo teria sofrido - e ainda sofre - com o que se pensa sobre ela, acarretando uma situação reducionista do pensamento mítico. Teria essa situação se iniciado no momento que a antropologia teria se afastado dos estudos dos fatos religiosos, propiciando que:

[...] amadores de diversas proveniências se aproveitassem disto para invadir o domínio da etnologia religiosa. Seus passatempos ingênuos se desenvolvem no terreno que deixamos baldio, e seus excessos se ajuntam à nossa carência, para comprometer o porvir de nossos trabalhos. (LÉVI-STRAUSS, 1970c, p. 225).

Lévi-Strauss (1970c, p. 225) ressalta que a origem desta situação se instaurou quando Tylor, Frazer e Durkheim - os fundadores da etnologia religiosa - reconheceram com mérito que os problemas de etnologia religiosa derivaram de uma psicologia estruturalista. É sabido que ambos estiveram atentos aos problemas psicológicos, embora nenhum deles tivesse formação psicológica.

Posto isso, os esforços dos fundadores da etnologia religiosa não foram suficientes, pois "suas interpretações passaram de moda tão rapidamente quanto os postulados psicológicos em que implicavam.” (LÉVI-STRAUSS, 1970c, p. 225). Teria esse episódio acarretado e reduzido à etnologia religiosa de forma que:

Teria sido necessário ampliar os quadros de nossa lógica, para incluir aí operações mentais, aparentemente diversas das nossas, mas que não deixam de ser de natureza intelectual. Em vez disto, tratou-se de reduzi-las a sentimentos informes e inefáveis. Este método, conhecido sob o nome de fenomenologia religiosa, se mostrou muitas vezes estéril e enfadonho. (LÉVISTRAUSS, 1970c, p. 225).

As consequências desse quadro vieram, por conseguinte, a refletir sobre a mitologia. O fato é que "de qualquer modo que se encarem os mitos, parecem-se reduzir todos a um passatempo gratuito ou a uma forma grosseira de especulação filosófica." (LÉVI-STRAUSS, 1970c, p. 226).

Em oposição, Queiroz (2013, p. 499) salienta que numa visão positiva o mito é tema relevante no estudo das religiões, pois sua presença acompanha os humanos desde os primórdios até hoje como uma das mais profundas expressões da compreensão de si e do mundo. 
Há quem propõe que a categoria de mito seja refletida sob a percepção histórica; a exemplo, Eliade (1972, p. 6) que relata que desde Xenófanes (séc. VI a.C.) existe uma ideia negativa em relação ao mito, pois foi este o primeiro a criticar e rejeitar as expressões mitológicas de Homero e Hesíodo. Foi a partir das primeiras manifestações do pensamento racional e das explicações filosóficas acerca do mundo e do ser humano com Sócrates, Platão e Aristóteles que despontou a visão do mito como fábula, invenção e ficção dando início à obra de "desmistificação" que se coaduna ao sentido etimológico da palavra, que é apreciada sob várias interpretações.

Queiroz (2013, p. 499) complementa que há autores que atribuem a palavra mito a uma raiz indo-européia "mud" que significa "pensar", "imaginar", "lembrar"; ou à matriz do antigo idioma egípcio, mdwj que significa "falar", "conversar". Grande parte dos autores recorre à raiz grega mythos, que se tornou comum a partir de Homero e expressa o sentido de "fala", "palavra falada", "história”, "fábula".

Contudo, para Eliade (1972, p. 9), é importante tomar cuidado no que tange à conceituação, sendo também indispensável estabelecer algumas ressalvas, uma vez que há certa dificuldade de se encontrar uma definição de mito que seja aceita por todos e, ao mesmo tempo, se mostre acessível aos não especialistas. Associa-se, este, ao fato da existência da crença de que o mito seja uma realidade cultural extremamente complexa que pode ser abordada e interpretada através de perspectivas múltiplas.

Com essa percepção, identificamos quão difícil é encontrar uma única definição capaz de cobrir todos os tipos e toda a abrangência do conceito de mito em todas as sociedades arcaicas e tradicionais.

Lévi-Strauss (1970c, p. 226) aponta duas vias que classificam como pretensiosas acerca da ideia de mito. A primeira deriva do pensamento que cada sociedade exprime, através dos mitos, seus sentimentos fundamentais. A segunda deriva da ideia de que os mitos constituem tentativas de explicação de fenômenos dificilmente compreensíveis. Posto isso, Lévi-Strauss (1970c, p. 226227) conclui que além de pretensiosas, tais vias reduziriam a mitologia apenas a um reflexo social, já que sua intenção é explicitar que a estrutura dos mitos se 
apresenta de forma exatamente igual independente do espaço ou sociedade em que habita, sendo então expressão de um elemento universal. Concluí também que os mitos se definem por ser um sistema temporário que combina as propriedades da língua e da fala.

O mito faz parte integrante da língua; é pela palavra que ele se nos dá a conhecer, ele provém do discurso. Se queremos perceber os caracteres específicos do pensamento mítico, devemos, pois, demonstrar que o mito está simultaneamente, na linguagem e além dela.[...]Saussure mostrou que a linguagem oferecia dois aspectos complementares: um estrutural, o outro estatístico; a língua pertence ao domínio de um tempo reversível, e a palavra, ao domínio de um tempo irreversível. (LÉVI-STRAUSS, 1970c, p. 228).

É o tempo que se encarrega pela diferenciação de mito e conto popular. Ou seja, o mito se realiza por intermédio de diversos códigos conforme aponta Lévi-Strauss (1970c, p. 229), dentre eles, a título de exemplo: códigos orais e códigos culturais como o astronômico, meteorológico, cosmológico, zoológico, botânico, psicoorgánico e tecnológico entre outros.

Lévi-Strauss, na obra $O$ feiticeiro e sua magia, propõe uma discussão pautada na perspectiva psicológica em torno do papel do mago, cujo pensamento é ilustrado de forma bastante rica de sentido a partir de um acontecimento em uma tribo do Novo México, que, de forma resumida, pretendemos fazer menção nesse momento. Trata-se do caso de um adolescente da tribo que é acusado de feitiçaria por ter - hipoteticamente - provocado uma crise nervosa em uma garota ao tocá-la às mãos. Como é de costume na tribo, o adolescente foi levado a julgamento mais de uma vez. O mesmo negou todas as acusações, contudo não conseguiu comprovar sua inocência. A tribo parecia não estar interessada na comprovação da inocência, mas sim, que o adolescente explicasse como adquiriu tais poderes. O adolescente, por vezes, foi a julgamento, até que percebeu que era inútil tentar comprovar sua inocência. Desse modo, muda de tática e decide conformar-se com a condição de feiticeiro e conta uma longa e detalhista história sobre como adquiriu seus poderes.

$\mathrm{Na}$ ótica de Lévi-Strauss, o que ocorre é uma tentativa de se estabelecer um equilíbrio entre o pensamento normal e o pensamento patológico do mago. O primeiro tem como característica reclamar sempre seu sentido às coisas que o recusam. O segundo extravasa de interpretações e de ressonâncias afetivas com as quais está sempre pronto a sobrecarregar uma realidade, que seria de outro 
modo deficitária. O autor salienta que "o adolescente chegou a se transformar, de ameaça para a segurança física de seu grupo, em garantia da sua coerência mental.” (LÉVI-STRAUSS, 1970a, p. 201).

Deste equilíbrio mental, surge o pensamento mágico que, segundo o antropólogo, se dá a partir da necessidade do homem que exige do pensamento mágico um novo sistema de referência, que permite que dados até então contraditórios passem a se integrar.

Identificamos, nesse exemplo, que é a partir de uma ação da tribo que se moldou um novo feiticeiro. $O$ próprio adolescente passa a não ter certeza de sua inocência devido a perfeição da história e do personagem que ele é levado a criar, passando a viver de fato na condição de um feiticeiro. Assim, a história e o personagem foram construídos a partir da demanda da tribo, a partir da necessidade do grupo de compreender a origem dos poderes mágicos portados pelo jovem, ou seja, nos remete a uma narrativa mítica de fundação de tais poderes.

Lévi-Strauss (1970a, p. 201) afirma que a mente humana tem uma estrutura para relacionar-se com o mundo. Entre estas características mentais universais estão a necessidade de classificar, ou seja, impor ordem sobre aspectos da natureza, sobre o relacionamento das pessoas com a natureza e sobre os relacionamentos entre as pessoas.

Este é um pensamento propício que circunda as mentes humanas em prol da associação que fazem da magia, restringindo-a majoritariamente ao campo do malefício e, muitas vezes, a termos envoltos num discurso vinculado ao charlatanismo. Sobre isso, Marcel Mauss afirma que:

Todos esses mitos dos magos encaixam-se uns nos outros, não teríamos de nos ocupar deles tão longamente se eles não fossem as marcas das opiniões sociais de que os magos são o objeto. Assim como o mago é definido por suas relações, com os animais, assim também ele é definido por suas relações com os espíritos e, em última análise, pelas qualidades da sua alma. (MAUSS, 2003, p. 76).

Percebe-se que as opiniões sociais exaltam a necessidade do ser humano de sofisticar a história dos fenômenos diante dos temas mitológicos rumo ao conhecimento e ao autoconhecimento, tornando o fazer mágico notório. 
No texto A eficácia simbólica, Lévi-Strauss propõe uma releitura do texto mágico-religioso publicado por Wassen e Holmer que trata dos aspectos de cura-xamãnística. Trata-se de um longo conto de encantamento que acontece durante um parto complicado onde a parturiente recorre ao xamã para concluir o procedimento. A psicologia aqui trabalhada visa o feiticeiro - o xamã, o doente e o público.

Percebemos que as técnicas utilizadas visam reconstruir de fato uma experiência real, onde o mito se entrelaça aos personagens. De forma que "a analogia entre os dois métodos seria mais completa ainda, se pudesse admitir como Freud, parece ter sugerido por duas vezes, que descrição em termos psicológicos da estrutura das psicoses e das neuroses deve desaparecer um dia diante de uma concepção fisiológica, ou mesmo bioquímica.” (LÉVI-STRAUSS, 1970b, p. 221). Isso acontece devido ao fato de que Freud, por vezes, ter ressaltado a presença das dimensões míticas na alma do homem moderno. $\mathrm{O}$ que chama a atenção é que:

Vai-se, pois, passar da realidade mais banal ao mito, do universo físico ao
universo fisiológico, do mundo exterior ao corpo interior. E o mito,
desenvolvendo-se no corpo interior, deverá conservar a mesma vivacidade, o
mesmo caráter de experiência vivida à qual, graças ao estado patológico e a
uma técnica obsidente apropriada, o xamã terá imposto as condições. (LÉVI-
STRAUSS, 197ob, p. 212).

Nessa perspectiva, o indivíduo aqui entendido como o xamã vive intensamente o mito no momento ritual. Fomentando essa discussão, Girard (1998, p. 117) faz saber que há duas teses que se dedicam a refletir a questão da gênese dos mitos e dos rituais:

A mais antiga remete ao ritual ao mito; ela busca no mito seja o acontecimento real, seja crença que fez nascer as práticas rituais. A segunda move-se no sentido inverso; ela remete ao ritual não apenas mitos e deuses, mas a tragédia e outras formas culturais gregas. (GIRARD, 1998, p. 117).

Girard (1998, p. 117-118) aborda a concepção do sacrifício que é evidenciado como o elemento-origem do ritual religioso, mas que subsiste a indagação de qual é a origem do próprio sacrifício. Isso se dá por que:

A partir do momento em que se utiliza um fenômeno para explicar outros, acredita-se geralmente não ser necessário explicar este próprio fenômeno. Sua 
transparência torna-se uma espécie de dogma não formulado. Aquilo que esclarece não tem necessidade de ser esclarecido. (GIRARD, 1998, p. 117-118).

No entanto, Lévi-Strauss ainda se indaga se o valor terapêutico da cura deve-se ao fato em si ou não está associado a uma "situação rememorada" o que o autor chama de "mito vivido". Entende-se que os mitos vivos são onde se fundamentam e justificam todo o comportamento e toda atividade do homem. Ou seja,

"Vivo" no sentido de que fornece os modelos para a conduta humana, conferindo, por isso mesmo, significação e valor à existência. Compreender a estrutura e a função dos mitos nas sociedades tradicionais não significa apenas elucidar uma etapa na história do pensamento humano, mas também compreender melhor uma categoria dos nossos contemporâneos. (Eliade, 1972, p. 6).

Ao pensarmos o Mito e Magia na modernidade, ressaltamos também a ideia de uma compreensão no nosso próprio modelo de civilização e nossa história como um todo. Não se trata de uma metodologia que elucida todas as questões passadas, mas que sim, abrem caminhos para se interpretar o momento atual à vista de um eterno retorno ao ato de fundação, na qual a interpretação mitológica favorece o processo.

Eliade (1972, p. 6) aproxima sua teoria às ideias de Claude Lévi-Strauss ao afirmar que os modernos não cultuam, não praticam e nem ritualizam os mitos; deste modo, eles não significam a sobrevivência de uma mentalidade, mas identifica que o mito enquanto crença fez nascer as práticas rituais, ou seja, a função simbólica, isto é, a representação mental que consolida-se na crença coletiva.

Quer seja o mito recriado pelo sujeito, quer seja tomado de empréstimo à tradição, ele só absorve de suas fontes, individual ou coletiva (entre as quais se produzem constantemente interpenetrações e trocas), o material de imagens que ele emprega; mas a estrutura permanece a mesma, e é por ela que a função simbólica se realiza. (LÉVI-STRAUSS, 1970c, p. 223).

Através de uma leitura mítica do papel do mago e da magia no senso religioso contemporâneo, que diz respeito à sensibilidade pessoal ou coletiva em relação a dimensão espiritual, que sofre alterações de tempos em tempos, mas 
que é contemporânea a seu próprio tempo e espaço, é possível perceber que a partir da organização do pensamento humano, da diversidade da cultura dos povos e principalmente da diversidade de linguagem é possível identificar a estrutura mitológica como experiência e dimensão construtiva na mente humana. Ressaltando que essa estrutura mitológica é permeada pelas mais diversas formas, mas que em suma está sempre em processo de ser rememorada. Isto é,

Um mito diz respeito, sempre, a acontecimentos passados: "antes da criação do mundo", ou "durante os primeiros tempos", em todo caso, "faz muito tempo". Mas o valor intrínseco atribuído ao mito provém de que estes acontecimentos, que decorrem supostamente em um momento do tempo. Formam também uma estrutura permanente. Esta se relaciona simultaneamente ao passado, ao presente e ao futuro. (LÉVI-STRAUSS, 1970c, p. 229).

Isso até que se chegue a esse momento em que nós nos estabelecemos, que denominamos por "senso religioso contemporâneo". Trata-se de uma discussão em torno dos anseios da atualidade, um momento cujas questões se mostram próximas do indivíduo, de forma mais íntima da sua subjetividade, sem se distanciar do que se denomina coletividade, a partir das configurações pelas quais passa a modernidade, o que incluí o exercício de se pensar a contemporaneidade sob a ótica da estrutura mitológica e das ferramentas que foram apontadas por Lévi-Strauss nesse ensaio.

As questões que fazem interface com esse movimento são em tudo, expressões que se destacam na contemporaneidade. A leitura mítica em prol da interpretação de diversas realidades, aqui neste texto sob o viés da magia, que se acentua como um tema contemporâneo está nesse sentido.

Pois, quando associado aos anseios da sociedade contemporânea, que se destaca por se questionar sob os acontecimentos passados para se compreender fenômenos, histórias, e a própria construção do modelo societário em quem vivemos a partir de uma reflexão mental para se objetivar a experiência utilizando-se dos mais diversos códigos humanos a fim de recuperar a importância da consciência e reflexão mítica para o ser humano contemporâneo. 


\section{REFERÊNCIAS}

ELIADE Mircea. Mito e realidade. Trad. Pola Civelli. 5ed. São Paulo: Perspectiva, 1972.

FRAZER, James. A magia simpática. O ramo de ouro. Rio de janeiro: Zahar, 1982.

GEERTZ. Clifford. A interpretação das culturas. Rio de Janeiro: LTC, 2008.

GIRARD, René. A violência e o sagrado. Trad. Martha Conceição Gambini. 2. Ed. São Paulo: Paz e Terra, 1998.

LÉVI-STRAUSS, Claude. O feiticeiro e sua magia. In: Antropologia estrutural. Rio de Janeiro: Tempo Brasileiro, 1970a.

LÉVI-STRAUSS, Claude. A eficácia simbólica. In: Antropologia estrutural. Rio de Janeiro: Tempo Brasileiro, 1970b.

LÉVI-STRAUSS, Claude. A estrutura dos Mitos. In: Antropologia estrutural. Rio de Janeiro: Tempo Brasileiro, 1970c.

LIDÓRIO, Ronaldo A. Conceituando a antropologia. Antropos - revista de Antropologia, Brasília, v. 3, ano 2, p. 7-15, dez. 2009.

MAUSS, Marcel. HUBERT, Henri. Esboço de uma teoria geral da magia. In:

Sociologia e Antropologia. Tradução de Paulo Neves. São Paulo: Cosac Naify, 2003.

QUEIROZ, José J. Mitos e suas regras. In: Passos, João D.; USARSKI, Frank. (Org.)

Compêndio de Ciência da Religião. São Paulo: Paulinas; São Paulo: Paulus, 2013. p. 499-511.

Recebido em: 21/o9/2016 Aprovado em: 23/03/2018 